\title{
Article
}

\section{Assessment of Fit on Ten Screw-Retained FrameworksRealized through Digital Full-Arch Implant Impression}

\author{
Maurizio De Francesco ${ }^{1}$, Edoardo Stellini ${ }^{1}$, Stefano Granata ${ }^{1}$, Sergio Mazzoleni ${ }^{1}$, \\ Francesco Saverio Ludovichetti ${ }^{1}$ (D), Carlo Monaco ${ }^{2}$ and Adolfo Di Fiore ${ }^{1, *}$ (D) \\ 1 Department of Neurosciences, School of Dentistry, Section of Prosthodontics and Digital Dentistry, \\ University of Padova, 35100 Padova, Italy; maurizio.defrancesco@unipd.it (M.D.F.); \\ edoardo.stellini@unipd.it (E.S.); stefano.granata@unipd.it (S.G.); sergio.mazzoleni@unipd.it (S.M.); \\ francesco.ludovichetti@unipd.it (F.S.L.) \\ 2 Department of Biomedical and Neuromotor Sciences (DIBINEM), Division of Prosthodontics and \\ Maxillofacial Rehabilitation, Alma Mater Studiorum-University of Bologna, 40121 Bologna, Italy; \\ carlo.monaco2@unibo.it \\ * Correspondence: adolfo.difiore@unipd.it
}

check for updates

Citation: De Francesco, M.; Stellini, E.; Granata, S.; Mazzoleni, S.; Ludovichetti, F.S.; Monaco, C.;

Di Fiore, A. Assessment of Fit on Ten Screw-Retained FrameworksRealized through Digital Full-Arch Implant Impression. Appl. Sci. 2021, 11, 5617. https://doi.org/10.3390/ app11125617

Academic Editor: Bruno Chrcanovic

Received: 18 May 2021

Accepted: 15 June 2021

Published: 18 June 2021

Publisher's Note: MDPI stays neutra with regard to jurisdictional claims in published maps and institutional affiliations.

Copyright: (C) 2021 by the authors Licensee MDPI, Basel, Switzerland. This article is an open access article distributed under the terms and conditions of the Creative Commons Attribution (CC BY) license (https:// creativecommons.org/licenses/by/ $4.0 /)$.
Abstract: Background: Discordant opinions have emerged among clinicians and researchers regarding a digital impression for full-arch implant-supported fixed dental prostheses (FDPs). The purpose of this study was to assess the fit of screw-retained milled frameworks on six implants realized from digital impressions through the Sheffield test. Methods: One patient received a maxillary full-arch implant-supported FDP. Six months after the surgical procedure, ten intraoral full-arch digital impressions were performed to mill ten frameworks. To clinically assess the fit, the Sheffield test was applied for all frameworks. The gaps among the frameworks and the implant analogs were measured using a microscope on the master model realized with a traditional impression. The Wilcoxon sum-rank test was used to compare the misfit value among the different implant positions. Results: The Sheffield test did not show gaps in the framework-implant interfaces when the screw was completely tightened on the more distal implant for all the milled frameworks. The mean misfit value calculated after microscope examination was $38 \pm 5 \mu \mathrm{m}$. Differences that were statistically significant emerged when the misfit values of central positions were compared with other values. Conclusions: The use of full-arch implant digital impressions represents a viable alternative to traditional impressions for the fabrication of implant-supported FDPs.

Keywords: digital impression; full-arch; CAD/CAM; intraoral scanner; dental implant

\section{Introduction}

Intraoral scanners (IOS) are becoming a commonly used tool in dental clinical practice [1]. A decrease in operative time and patient discomfort and increased accuracy represent the main advantages that digital technology has introduced into clinical practice [2,3]. Regarding the digital impression for single crowns [4,5] or three-unit fixed dental prostheses (FDPs) [6], several authors have demonstrated the better performance of a digital workflow. However, discordant opinions have emerged among clinicians and researchers regarding a digital impression for full-arch implant-supported FDPs.

In the literature, most studies that have investigated this topic were conducted in vitro and the findings showed that not all IOS were suitable for digital impressions in full-arch implant-supported FDPs [7-14]. The correct execution of an impression in prosthodontics is fundamental to avoid a misfit among the interface of the implant and the prosthesis and consequently an increased risk of mechanical and biological complications [15]. An acceptable misfit value was reported by several authors; however, there are different opinions. Branemark et al. [16] classified a misfit as a value above $10 \mu \mathrm{m}$, Jemt [17] declared as acceptable any values less than $150 \mu \mathrm{m}$, and, conversely, Di Fiore et al. [7] believed that the misfit value should be below 30-50 $\mu \mathrm{m}$. 
To the best of the authors' knowledge, there are three articles that have investigated in vivo the accuracy of the digital impression for full-arch implant-supported FDPs [18-20]. In two articles, the authors compared the implant-supported FDPs on four implants realized using digital and traditional impressions through panoramic radiographs during the follow-up examinations. No signs of misfit were identified among the framework and implants $[18,19]$. However, the third clinical trial compared the accuracy of digital versus conventional full-arch implant impressions of edentulous patients [20]. The authors demonstrated the possibility of fabricating a maxillary fixed complete denture using a digital impression. However, the authors did not realize frameworks but calculated the 3D deviations between the Standard Tessellation Language (STL) files from the intraoral digital scan and the STL files from extraoral digitalized final stone casts.

Clinical assessment of the passive fit between framework and implants is difficult [21]. Several methods have been suggested, but they all have their limitations. However, the Sheffield test, radiographs, visual inspection, and tactile sensation are considered the most common clinical evaluation methods [21-23] and are sometimes used in laboratory research [24]. The fit of implant-supported FDPs made from the conventional impression is well described in the literature $[15,24]$, while there is a lack of research regarding the clinical evaluation of the fit of full-arch implant-supported FDPs realized through the digital workflow.

Therefore, the aim of this clinical trial was to evaluate the fit of screw-retained milled frameworks on six implants realized from digital impressions through the Sheffield test and radiographs. Moreover, the misfit value was measured using a microscope on a printed master model. The null hypothesis was that all the frameworks would show comparable fit without any difference.

\section{Materials and Methods}

A 58-year-old woman with no problematic medical history (ASA 1) presented to the dental office with the chief complaint of dental pain, tooth mobility, and unsatisfactory esthetics (Figure 1).

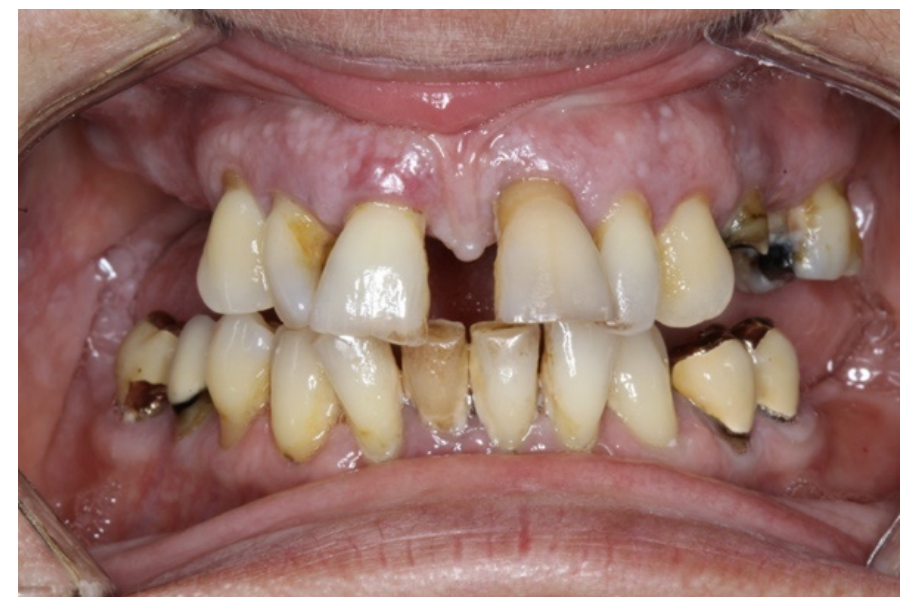

Figure 1. Initial clinical situation.

The clinical and radiographic examination revealed several missing teeth, bleeding, plaque, and periodontal disease (Stage IV, Grade C). The patient did not report any articular or muscular symptoms. The preliminary treatment plan focused on the periodontal chart and non-surgical periodontal treatment in both arches. After re-evaluations and a diagnostic wax-up, different possible definitive treatments were discussed with the patient, including risks, benefits, and costs. The patient wished to rehabilitate only the upper arch through a full-arch implant-supported FDP. Cone beam computed tomography was prescribed to plan the implant placements. The presented study was performed in private 
practice, in accordance with the Declaration of Helsinki of 1964, as revised in 2013, as Good Clinical Research Practice requires. The operator asked the patient to give full and informed consent before inclusion within the protocol.

In the first surgery step, all teeth except elements 13 and 23 were extracted and dental implants (Tapered Screw-Vent Implant, Zimmer Biomet, Conegliano, Italy) in locations $16,14,12,22,24$, and 16 were placed. Teeth 13 and 23 were prepared with an abutment tooth to support a temporary prosthesis realized by using the diagnostic wax-up. After 4 months, temporary abutments were screwed into the implants, the temporary prosthesis was relined using the abutment teeth as support, and elements 13 and 23 were extracted. After a 1-month period to allow for the healing of the soft tissue, the digital impressions were performed using the IOS (iTero Align, Align Technology, Tempe, AZ, USA). Six scan-bodies (Gentek, Zimmer Biomet, Conegliano, Italy) were tightened with a special screwdriver (Zimmer Biomet, Conegliano, Italy) and a manual torque-controlled ratchet (15 Ncm), and 10 full-arch digital implant impressions were acquired according to the manufacturer's instructions (Figure 2).
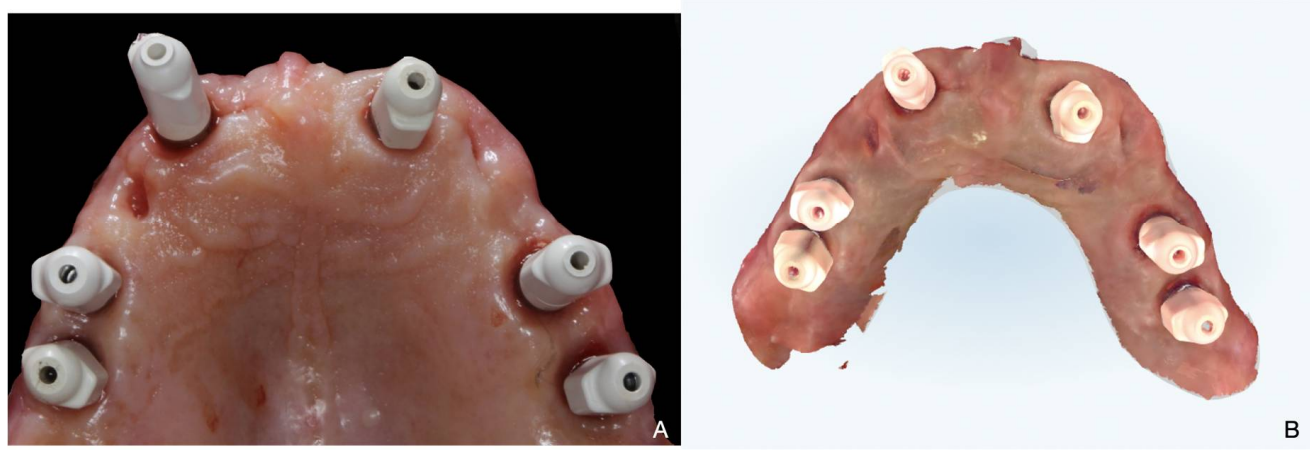

Figure 2. (A) Occlusal view of the clinical situation before digital impression. (B) Occlusal view of the intraoral digital impression.

After scanning the antagonists, a buccal scan with teeth in maximum intercuspation position as a bite registration was performed. During scanning, a dry field was maintained using a dental aspirator. The implant-supported temporary prosthesis was acquired to transfer the vertical dimension, shape, and occlusal morphology to the definitive prosthesis [5]. The 10 STL files were uploaded to CAD software (Exocad, Exocad DentaCad, Darmstadt, Germany) to design the frameworks. Successively, 10 titanium frameworks were realized with a 5-axis milling machine (Zfx in-house 5X, Zimmer Biomet, Conegliano, Italy) (Figure 3).

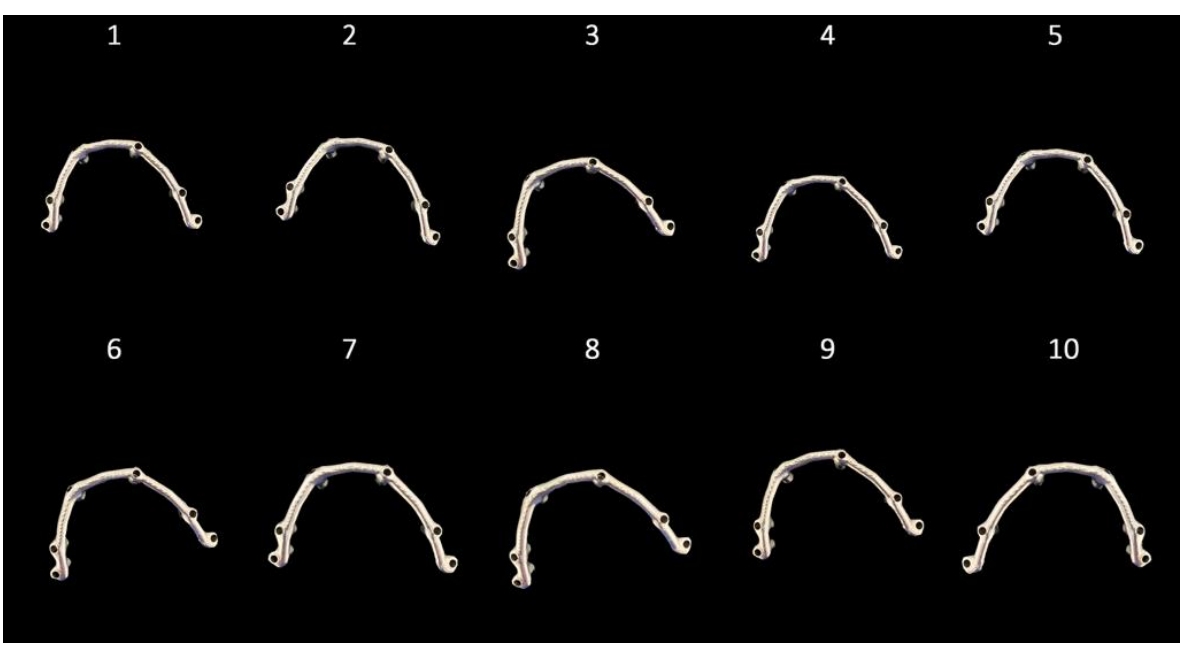

Figure 3. Occlusal view of the 10 milled frameworks. 
Moreover, a traditional impression by using coping pick-up and the open tray technique was used to realize a master model [15].

The passive fit was assessed by the Sheffield test, screwing each framework onto the mouth of the patient. According to this test, the framework presented a passive fit when one screw on the distal abutment was completely tightened without creating a gap among the other framework-implant interfaces. If the fit was not sufficient, the superstructure was lifted when a screw was tightened, creating a gap at the level of one or more abutment analogs [21,22] (Figure 4).

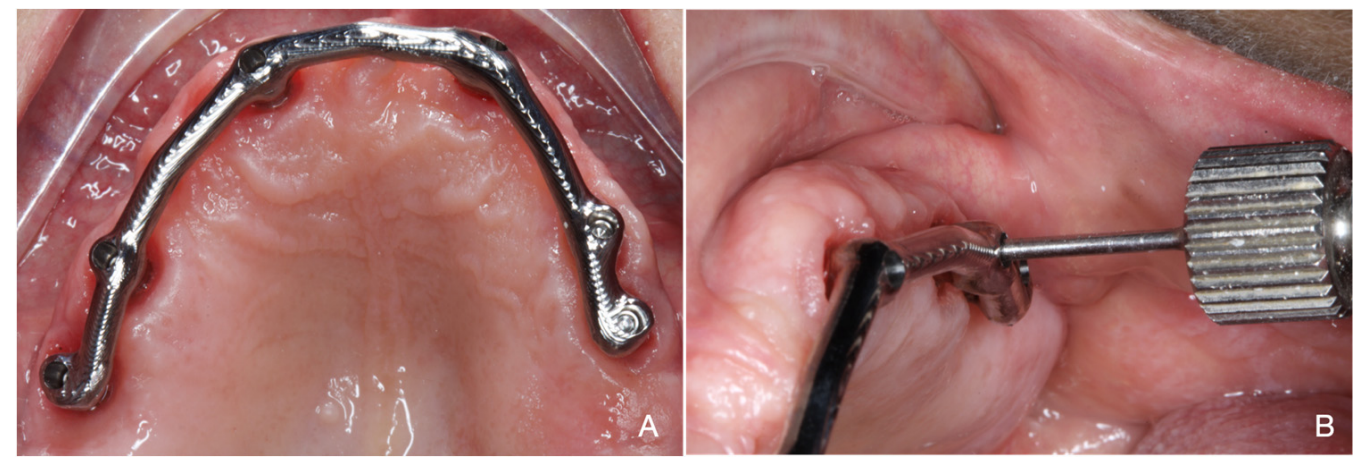

Figure 4. Occlusal view of one milled framework screwed onto the mouth of patient (A). The Sheffield test applied (B).

In addition, the frameworks were screwed onto the master model to measure the interface among frameworks and implants by using a digital microscope (AM7915MZL, Dino-Lite Microscope, Almere, The Netherlands) at 150× magnification (Figure 5).
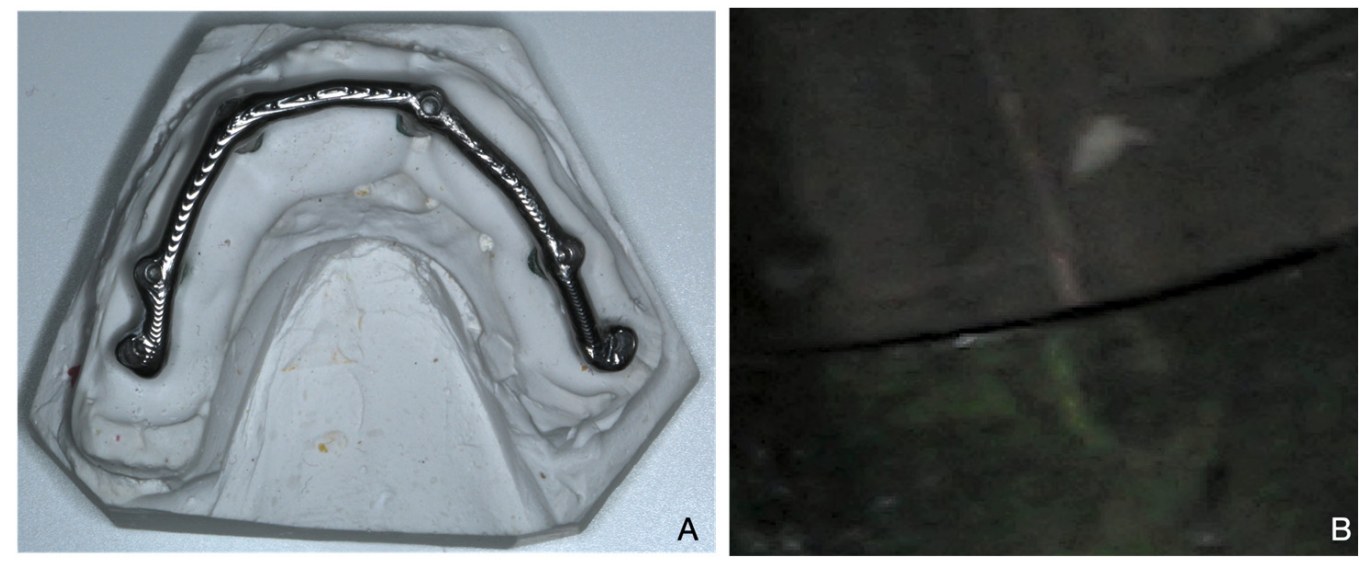

Figure 5. Occlusal view of one milled framework screwed onto master model (A). Gap among framework and analog at $150 \times$ magnification $(\mathbf{B})$.

For each framework, we obtained 6 measurements. The average of the 6 measurements was considered as the overall misfit value for the framework. Descriptive statistical analysis was performed. Average and standard deviations were calculated. Comparative statistical analysis was performed to compare the misfit value among the different implant positions. The non-parametric Wilcoxon sum-rank test was used with $\alpha=0.05$ and statistical power of $80 \%$. Regarding the radiograph examination, a random selection of only one framework was chosen. A customized X-ray holder was realized and the film was placed as perpendicular as possible to the long axis of the implant-framework interface to improve the accuracy of the radiographs. After the fit evaluation of the frameworks, one of these was used to realize the definitive implant-supported FDP. 


\section{Results}

For the clinical examinations, the Sheffield test did not show gaps among frameworkimplant interfaces when the screw was completely tightened on the more distal implant for all the milled frameworks. The same result emerged also after the examination of the master model. After microscope analysis, the mean misfit value was $38 \pm 5 \mu \mathrm{m}(\mathrm{min}=34$ Max $=44)$ for all the frameworks. The results are reported in Table 1.

Table 1. In vitro analysis of the Sheffield test outcomes for the frameworks.

\begin{tabular}{|c|c|c|c|c|c|c|c|c|}
\hline Framework & $\underset{(\mu \mathrm{m})}{\operatorname{Implant} 1}$ & $\underset{(\mu \mathrm{m})}{\operatorname{Implant} 2}$ & $\begin{array}{c}\text { Implant } 3 \\
(\mu \mathrm{m})\end{array}$ & $\begin{array}{c}\text { Implant } 4 \\
(\mu \mathrm{m})\end{array}$ & $\underset{(\mu \mathrm{m})}{\text { Implant } 5}$ & $\begin{array}{c}\text { Implant } 6 \\
(\mu \mathrm{m})\end{array}$ & $\begin{array}{c}\text { Mean } \\
(\mu \mathrm{m})\end{array}$ & SD \\
\hline 1 & 35 & 33 & 44 & 45 & 38 & 33 & 38 & 5 \\
\hline 2 & 43 & 39 & 46 & 51 & 44 & 41 & 44 & 4 \\
\hline 3 & 35 & 33 & 42 & 45 & 36 & 38 & 38 & 5 \\
\hline 4 & 38 & 35 & 36 & 33 & 33 & 35 & 35 & 2 \\
\hline 5 & 40 & 39 & 48 & 44 & 38 & 37 & 41 & 4 \\
\hline 6 & 28 & 31 & 39 & 41 & 33 & 30 & 34 & 5 \\
\hline 7 & 30 & 32 & 39 & 51 & 37 & 33 & 37 & 8 \\
\hline 8 & 31 & 31 & 44 & 41 & 29 & 30 & 34 & 6 \\
\hline 9 & 32 & 34 & 41 & 40 & 37 & 36 & 37 & 3 \\
\hline 10 & 44 & 38 & 40 & 53 & 43 & 45 & 44 & 5 \\
\hline Mean & 35 & 34 & 42 & 45 & 37 & 36 & & \\
\hline SD & 5 & 3 & 4 & 6 & 4 & 5 & & \\
\hline
\end{tabular}

Differences that were statistically significant emerged among the misfit values of the implant in positions: 1 versus $3(p=0.004), 1$ versus $4(p<0.001), 2$ versus $3(p<0.001), 2$ versus $4(p<0.001), 3$ versus $5(p=0.006), 3$ versus $6(p=0.002), 4$ versus $5(p=0.002)$, and 4 versus $6(p<0.001)$. No statistical differences were found with the remaining combination. Within the limitations of the radiograph examination, the RX did not show any clinical misfit between the framework chosen and the implants (Figure 6).

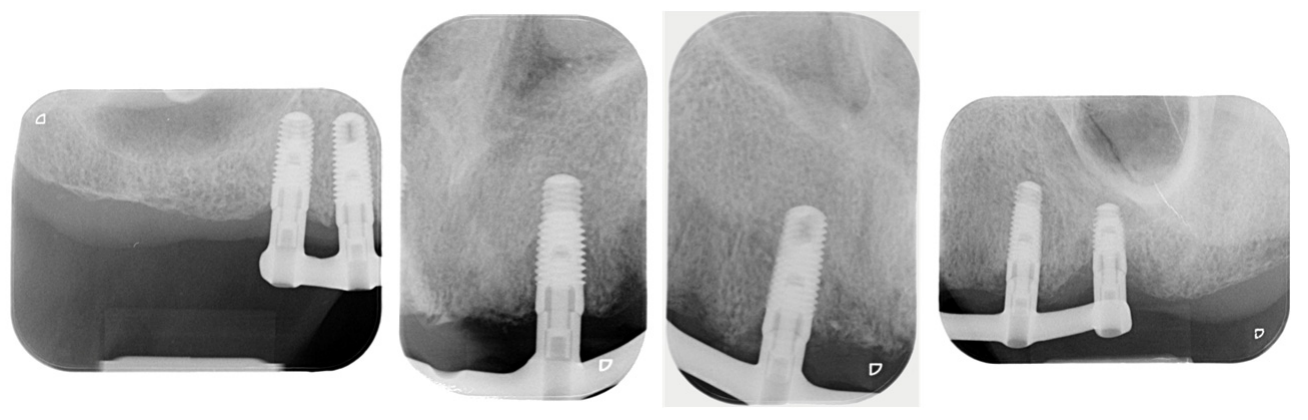

Figure 6. Radiograph examinations.

\section{Discussion}

None of the frameworks realized by full-arch digital impressions showed misfit, either clinically onto the patient or onto the master model. Moreover, the radiograph examinations performed on the randomized framework did not reveal any misfit either.

The passive fit can be assessed using two methods: in vivo and in vitro. Clinically, various techniques have been introduced; however, none has gained full acceptance as a thorough test [25]. The Sheffield test, finger pressure, visual inspection, tactile sensations, radiographs, and screw-resistant test are the main in vivo methods described in the literature to assess the implant-framework gap, but every procedure has merits and limitations $[21,22,25]$.

The major studies published in the literature assessed the marginal fit of a single crown on an abutment tooth. Di Fiore et al. [26] investigated the range of values for the marginal and internal fit of a single crown on an abutment tooth. The findings highlighted 
the better marginal fit ( $55.01 \pm 7 \mu \mathrm{m})$ of the coping realized by using a digital impression than from traditional impressions $(75.04 \pm 13 \mu \mathrm{m})$. However, both the mean values were clinically acceptable. The same results were reported in a recent article where the authors investigated the marginal fit of crowns generated by using digital impressions realized with several intraoral scanners [27]. The authors reported an average marginal gap value of $53.45 \pm 30.52 \mu \mathrm{m}$. The minimum mean value was recorded by using PlanScan $(40.04 \pm 18.90 \mu \mathrm{m})$; meanwhile, the maximum mean value $(67.95 \pm 30.41 \mu \mathrm{m})$ was recorded by TRIOS 3 . The other intraoral scanners yielded the following average marginal gap values: 3D PROGRESS Plus (40.20 $\pm 21.91 \mu \mathrm{m})$, True Definition Scanner $(40.82 \pm 26.19 \mu \mathrm{m})$, $\mathrm{CS} 3500^{\circledR}(54.82 \pm 28.86 \mu \mathrm{m}) \operatorname{CS} 3600(5967 \pm 28.72 \mu \mathrm{m})$, Omnicam $(61.57 \pm 38.59 \mu \mathrm{m})$, and DWIO $(62.49 \pm 31.54 \mu \mathrm{m})$ [27].

Regarding the passive fit generated by digital full-arch implant impressions, few in vivo studies have been conducted. To the best of the authors' knowledge, there are only three studies [18-20].

Gherlone et al. [18] demonstrated that it is possible to manufacture a CAD/CAM cobalt-chromium full-arch framework following a digital impression. After implant placement, 25 patients were rehabilitated with an "all on four" technique following the digital or conventional workflow. No misfit emerged through panoramic radiographs after 3-, 6-, and 12-month follow-up examinations. A similar result was reported by Capparè et al. [19], who analyzed the success of full-arch maxillary rehabilitation after 24 months. X-ray examinations revealed no clinical misfit among frameworks and implants.

The investigation conducted by Chochlidakis et al. [20] had a different purpose. The authors compared the accuracy of digital and conventional implant impressions for completely edentulous patients without assessing the framework fit. The authors calculated the 3D deviations between the virtual casts from intraoral full-arch digital scans and digitized final stone casts generated from conventional implant impressions. The results of the 3D deviations were $162 \pm 77 \mu \mathrm{m}$. The findings did not display any misfit among implant and framework, but the superimposition of two virtual casts. Therefore, it is difficult to interpret the results due to the lack of consideration of milled frameworks. Moreover, the average value reported is beyond the clinically acceptable threshold [15-17].

However, several in vitro articles demonstrated better fit values for the digital rather than the traditional approach [24,28]. Menini et al. [28] compared different impression techniques on multiple implants by using a coordinate measurement machine (CMM). After CMM analysis, the best and the worst casts generated using digital and traditional impressions were selected to mill titanium frameworks. The Sheffield test showed that the framework milled by the worst cast generated using the traditional impression presented the highest mean gap value $(63 \mu \mathrm{m})$. Therefore, the digital impressions represent a viable alternative to traditional impressions to realize the framework of full-arch implantsupported FDPs. Furthermore, Pesce et al. [24] reported a mean misfit value $<30 \mu \mathrm{m}$ for the framework of a full-arch implant-supported FDP realized using a digital impression. Similar results were obtained in this research, where the average misfit value was $38 \pm 5 \mu \mathrm{m}$. The statistical analysis showed significant differences among the misfit values of implants in central positions compared with the other values. Indeed, the mean misfit values in positions 3 and 4 were $42 \mu \mathrm{m}$ and $45 \mu \mathrm{m}$, respectively. The mean values were higher than the misfit mean values in the other positions. This result reveals a possible issue that the IOS may encounter during the acquisition of the central area due to the arch. Therefore, the correct scan strategy is fundamental to avoid this problem. The choice of the best impression techniques is a strategic step to ensure success and survival in prosthetic rehabilitation. With the increasing interest in the digital field, clinical articles may be useful to illustrate the advantages and disadvantages of these devices.

This research presents several limitations. The first is the impossibility of analyzing in vivo the mean value of misfit for the framework. Instead, we utilized an in vitro procedure where the interface among the analog and framework is measured with the use of a microscope. The second limitation is the use of only the Sheffield test to assess the 
in vivo misfit. Another limitation is that the X-ray examination was conducted only on one framework; therefore, the result cannot be generalized to other frameworks. The reason for this was to prevent unnecessary exposure of the patient to radiation.

However, this study suggests only that the digital implant impression with the iTero represents a valid method to mill full-arch implant frameworks. The result is not applicable to all intra-oral scanners; therefore, further in vivo studies are required to investigate the performance of other devices.

\section{Conclusions}

Within the limitations of this study, the digital full-arch implant impression represents a valid alternative to realize a complete arch framework with a passive fit below the threshold value.

Author Contributions: Conceptualization, M.D.F. and M.D.F.; methodology, A.D.F.; validation, E.S., S.M. and S.G.; formal analysis, F.S.L.; investigation, M.D.F.; data curation, A.D.F.; writing-original draft preparation, A.D.F.; writing — review and editing, C.M.; visualization, A.D.F.; supervision, A.D.F.; project administration, A.D.F. All authors have read and agreed to the published version of the manuscript.

Funding: This research received no external funding.

Institutional Review Board Statement: The study was conducted according to the guidelines of the Declaration of Helsinki. Ethical review and approval were waived for this study, as no experimentation was conducted on the patient.

Informed Consent Statement: Informed consent was obtained from the subject involved in the study. Written informed consent has been obtained from the patient to publish this paper.

Data Availability Statement: Data Availability Statements in section "MDPI Research Data Policies" at https:/ / www.mdpi.com/ethics, accessed on 17 June 2021. Page: 7.

Conflicts of Interest: The authors declare no conflict of interest.

\section{References}

1. Chochlidakis, K.M.; Papaspyridakos, P.; Geminiani, A.; Chen, C.J.; Feng, I.J.; Ercoli, C. Digital versus conventional impressions for fixed prosthodontics: A systematic review and meta-analysis. J. Prosthet. Dent. 2016, 116, 184-190. [CrossRef]

2. Granata, S.; Giberti, L.; Vigolo, P.; Stellini, E.; Di Fiore, A. Incorporating a facial scanner into the digital workflow: A dental technique. J. Prosthet. Dent. 2020, 123, 781-785. [CrossRef]

3. Di Fiore, A.; Vigolo, P.; Graiff, L.; Stellini, E. Digital vs Conventional Workflow for Screw-Retained Single-Implant Crowns: A Comparison of Key Considerations. Int. J. Prosthodont. 2018, 31, 577-579. [CrossRef]

4. Malaguti, G.; Rossi, R.; Marziali, B.; Esposito, A.; Bruno, G.; Dariol, C.; Di Fiore, A. In vitro evaluation of prosthodontic impression on natural dentition: A comparison between traditional and digital techniques. Oral. Implantol. (Rome) 2017, 14, 21-27. [CrossRef] [PubMed]

5. Di Fiore, A.; Monaco, C.; Brunello, G.; Granata, S.; Stellini, E.; Yilmaz, B. Automatic Digital Design of the Occlusal Anatomy of Monolithic Zirconia Crowns Compared to Dental Technicians' Digital Waxing: A Controlled Clinical Trial. J. Prosthodont. 2021, 30, 104-110. [CrossRef]

6. Ceruso, F.M.; Barnaba, P.; Mazzoleni, S.; Ottria, L.; Gargari, M.; Zuccon, A.; Bruno, G.; Di Fiore, A. Implant-abutment connections on single crowns: A systematic review. Oral. Implantol. (Rome) 2017, 10, 349-353. [CrossRef] [PubMed]

7. Di Fiore, A.; Meneghello, R.; Graiff, L.; Savio, G.; Vigolo, P.; Monaco, C.; Stellini, E. Full arch digital scanning systems performances for implant-supported fixed dental prostheses: A comparative study of 8 intraoral scanners. J. Prosthodont. Res. 2019, 63, 396-403. [CrossRef] [PubMed]

8. Mangano, F.G.; Admakin, O.; Bonacina, M.; Lerner, H.; Rutkunas, V.; Mangano, C. Trueness of 12 intraoral scanners in the full-arch implant impression: A comparative in vitro study. BMC Oral. Health 2020, 20, 263. [CrossRef] [PubMed]

9. Bilmenoglu, C.; Cilingir, A.; Geckili, O.; Bilhan, H.; Bilgin, T. In vitro comparison of trueness of 10 intraoral scanners for implant-supported complete-arch fixed dental prostheses. J. Prosthet. Dent. 2020, 124, 755-760. [CrossRef]

10. Çakmak, G.; Yilmaz, H.; Treviño, A.; Kökat, A.M.; Yilmaz, B. The effect of scanner type and scan body position on the accuracy of complete-arch digital implant scans. Clin. Implant. Dent. Relat. Res. 2020, 22, 533-541. [CrossRef]

11. Mizumoto, R.M.; Yilmaz, B.; McGlumphy, E.A., Jr.; Seidt, J.; Johnston, W.M. Accuracy of different digital scanning techniques and scan bodies for complete-arch implant-supported prostheses. J. Prosthet. Dent. 2020, 123, 96-104. [CrossRef] 
12. Mizumoto, R.M.; Alp, G.; Özcan, M.; Yilmaz, B. The effect of scanning the palate and scan body position on the accuracy of complete-arch implant scans. Clin. Implant. Dent. Relat. Res. 2019, 21, 987-994. [CrossRef] [PubMed]

13. Mennito, A.S.; Evans, Z.P.; Nash, J.; Bocklet, C.; Lauer, K.A.; Bacro, T.; Cayouette, M.; Ludlow, M.; Renne, W.G. Evaluation of the trueness and precision of complete arch digital impressions on a human maxilla using seven different intraoral digital impression systems and a laboratory scanner. J. Esthet. Restor. Dent. 2019, 31, 369-377. [CrossRef] [PubMed]

14. Monaco, C.; Arena, A.; Pallotti, G.; di Fiore, A.; Scheda, L. Digital bar prototype technique for full-arch rehabilitation on implants. J. Am. Dent. Assoc. 2019, 150, 549-555. [CrossRef] [PubMed]

15. Di Fiore, A.; Meneghello, R.; Savio, G.; Sivolella, S.; Katsoulis, J.; Stellini, E. In Vitro Implant Impression Accuracy Using a New Photopolymerizing SDR Splinting Material. Clin. Implant. Dent. Relat. Res. 2015, 17 (Suppl. S2), e721-e729. [CrossRef] [PubMed]

16. Adell, R.; Eriksson, B.; Lekholm, U.; Brånemark, P.; Jemt, T. Long-term follow-up study of osseointegrated implants in the treatment of totally edentulous jaws. Int. J. Oral. Maxillofac. Implants 1990, 5, 347-359.

17. Jemt, T. Failures and complications in 391 consecutively inserted fixed prostheses supported by Brånemark implant in the edentulous jaw: A study of treatment from the time of prostheses placement to the first annual check-up. Int. J. Oral. Maxillofac. Implants 1991, 6, 270-276.

18. Gherlone, E.; Capparé, P.; Vinci, R.; Ferrini, F.; Gastaldi, G.; Crespi, R. Conventional Versus Digital Impressions for "All-on-Four" Restorations. Int. J. Oral. Maxillofac. Implants 2016, 31, 324-330. [CrossRef]

19. Cappare, P.; Sannino, G.; Minoli, M.; Montemezzi, P.; Ferrini, F. Conventional versus Digital Impressions for Full Arch ScrewRetained Maxillary Rehabilitations: A Randomized Clinical Trial. Int. J. Environ. Res. Public. Health 2019, 16, 829. [CrossRef]

20. Chochlidakis, K.; Papaspyridakos, P.; Tsigarida, A.; Romeo, D.; Chen, Y.W.; Natto, Z.; Ercoli, C. Digital Versus Conventional Full-Arch Implant Impressions: A Prospective Study on 16 Edentulous Maxillae. J. Prosthodont. 2020, 29, 281-286. [CrossRef]

21. Abduo, J.; Bennani, V.; Waddell, N.; Lyons, K.; Swain, M. Assessing the fit of implant fixed prostheses: A critical review. Int. J. Oral. Maxillofac. Implants 2010, 25, 506-515. [PubMed]

22. Jemt, T. In vivo measurements of precision of fit involving implant supported prostheses in the edentulous jaw. Int. J. Oral. Maxillofac. Implants 1996, 11, 151-158. [PubMed]

23. Kan, J.Y.; Rungcharassaeng, K.; Bohsali, K.; Goodacre, C.J.; Lang, B.R. Clinical methods for evaluating implant framework fit. J. Prosthet. Dent. 1999, 81, 7-13. [CrossRef]

24. Pesce, P.; Pera, F.; Setti, P.; Menini, M. Precision and Accuracy of a Digital Impression Scanner in Full-Arch Implant Rehabilitation. Int. J. Prosthodont. 2018, 31, 171-175. [CrossRef] [PubMed]

25. Yanase, R.; Binon, P.; Jemt, T.; Gulbransen, H.; Parel, S. How do you test a cast framework fit for a full-arch fixed implant supported prosthesis? Int. J. Oral. Maxillofac. Implants 1994, 9, 469-474.

26. Di Fiore, A.; De Francesco, M.; Monaco, C.; Stocco, E.; Vigolo, P.; Stellini, E. Comparison of accuracy of single crowns generated from digital and conventional impressions: An in vivo controlled trial. J. Osseointegr. 2019, 11, 107-112.

27. Ferrini, F.; Sannino, G.; Chiola, C.; Capparé, P.; Gastaldi, G.; Gherlone, E.F. Influence of Intra-Oral Scanner (I.O.S.) on The Marginal Accuracy of CAD/CAM Single Crowns. Int. J. Environ. Res. Public. Health 2019, 16, 544. [CrossRef]

28. Menini, M.; Setti, P.; Pera, F.; Pera, P.; Pesce, P. Accuracy of multi-unit implant impression: Traditional techniques versus a digital procedure. Clin. Oral. Investig. 2018, 22, 1253-1262. [CrossRef] 